\title{
Performance of the Omnipod Personalized Model Predictive Control Algorithm with Meal Bolus Challenges in Adults with Type 1 Diabetes
}

\author{
Bruce A. Buckingham, MD, Mark P. Christiansen, MD, Gregory P. Forlenza, MD, \\ R. Paul Wadwa, MD, Thomas A. Peyser, $\mathrm{PhD}^{4}$, Joon Bok Lee, $\mathrm{PhD}^{5}$ \\ Jason $\mathrm{O}^{\prime}$ Connor, BS, Eyal Dassau, $\mathrm{PhD}^{6}$ Lauren M. Huyett, $\mathrm{PhD}^{5}$ \\ Jennifer E. Layne, PhD, and Trang T. Ly, MBBS, FRACP, PhD
}

\begin{abstract}
Background: This study assessed the safety and performance of the Omnipod ${ }^{\circledR}$ personalized model predictive control (MPC) algorithm using an investigational device in adults with type 1 diabetes in response to overestimated and missed meal boluses and extended boluses for high-fat meals.

Materials and Methods: A supervised 54-h hybrid closed-loop (HCL) study was conducted in a hotel setting after a 7-day outpatient open-loop run-in phase. Adults aged 18-65 years with type 1 diabetes and HbA1c $6.0 \%-10.0 \%$ were eligible. Primary endpoints were percentage time in hypoglycemia $<70 \mathrm{mg} / \mathrm{dL}$ and hyperglycemia $\geq 250 \mathrm{mg} / \mathrm{dL}$. Glycemic responses for $4 \mathrm{~h}$ to a $130 \%$ overestimated bolus and a missed meal bolus were compared with a $100 \%$ bolus for identical meals, respectively. The 12-h postprandial responses to a high-fat meal were compared using either a standard or extended bolus.

Results: Twelve subjects participated in the study, with (mean \pm standard deviation): age $35.4 \pm 14.1$ years, diabetes duration $16.5 \pm 9.3$ years, $\mathrm{HbA} 1 \mathrm{c} 7.7 \pm 0.9 \%$, and total daily dose $0.58 \pm 0.19 \mathrm{U} / \mathrm{kg}$. Outcomes for the $54-\mathrm{h}$ HCL period were mean glucose $153 \pm 15 \mathrm{mg} / \mathrm{dL}$, percentage time $<70 \mathrm{mg} / \mathrm{dL}$ [median (interquartile range)]: $0.0 \%(0.0-1.2 \%), 70-180 \mathrm{mg} / \mathrm{dL}: 76.1 \% \pm 8.0 \%$, and $\geq 250 \mathrm{mg} / \mathrm{dL}: 4.5 \% \pm 3.6 \%$. After both the $100 \%$ and $130 \%$ boluses, postprandial percentage time $<70 \mathrm{mg} / \mathrm{dL}$ was $0.0 \%(0.0-0.0 \%)(P=0.50)$. After the $100 \%$ and missed boluses, postprandial percentage time $\geq 250 \mathrm{mg} / \mathrm{dL}$ was $0.2 \% \pm 0.6 \%$ and $10.3 \% \pm 16.5 \%$, respectively $(P=0.06)$. Postprandial percentages time $\geq 250 \mathrm{mg} / \mathrm{dL}$ and $<70 \mathrm{mg} / \mathrm{dL}$ were similar with standard or extended boluses for a high-fat meal.

Conclusions: The Omnipod personalized MPC algorithm performed well and was safe during day and night use in response to overestimated, missed, and extended meal boluses in adults with type 1 diabetes.
\end{abstract}

Keywords: Artificial pancreas, Automated insulin delivery, Closed-loop, Omnipod, tubeless Insulin pump, Postprandial.

\footnotetext{
${ }^{1}$ Division of Pediatric Endocrinology, Department of Pediatrics, Stanford University, Stanford, California.

${ }^{2}$ Diablo Clinical Research, Walnut Creek, California.

${ }^{3}$ Barbara Davis Center for Diabetes, University of Colorado School of Medicine, Aurora, Colorado.

${ }_{5}^{4}$ ModeAGC LLC, Palo Alto, California.

${ }^{5}$ Insulet Corporation, Billerica, Massachusetts.

${ }^{6}$ Harvard John A. Paulson School of Engineering and Applied Sciences, Harvard University, Cambridge, Massachusetts.

Data included in this article were presented, in part, at the 11th International Conference on Advanced Technologies \& Treatments for Diabetes in Vienna, Austria, on February 14-17, 2018, and the Diabetes Technology Meeting in Bethesda, MD, on November 2-4, 2017.

(C) Bruce A. Buckingham, et al., 2018; Published by Mary Ann Liebert, Inc. This Open Access article is distributed under the terms of the Creative Commons License (http://creativecommons.org/licenses/by/4.0), which permits unrestricted use, distribution, and reproduction in any medium, provided the original work is properly credited.
} 


\section{Introduction}

A RTIFICIAL PANCREAS (AP) system development is an area of intense interest and rapid growth, with many patients, caregivers, and healthcare providers recognizing the potential of automated insulin delivery systems to improve glycemic outcomes and reduce the burden of diabetes care. ${ }^{1-5}$ Nearly every component of an AP system can be customized from a variety of available options, potentially leading to differences in system usability and performance. ${ }^{6-8}$ The algorithm driving insulin delivery (and glucagon for dualhormone systems) for commercially available AP systems must be sufficiently robust to handle challenges to glycemic control that will be encountered as part of everyday use, while maintaining safety as the highest priority. 7,9

First-generation hybrid closed-loop (HCL) systems will require the user to give meal boluses based on estimated meal carbohydrate (CHO) content and, as with current open-loop (OL) therapy, some boluses will be overestimated, underestimated, or missed. ${ }^{10-12}$ For example, Meade and Rushton reported that adults with diabetes scored an average of $59 \%$ on correctly estimating the $\mathrm{CHO}$ content of foods they ate frequently, with $82 \%$ overestimating $\mathrm{CHO}$ content by an average of $40 \%{ }^{12}$ This would result in an overestimation of the meal bolus amount and increase the risk of hypoglycemia. An overestimated bolus may also occur when the user delivers a bolus for but does not consume his or her entire meal.

There have been a limited number of studies examining the ability of single- and dual-hormone AP systems to safely respond to common real-life use cases of overestimated, underestimated, or missed meal boluses. ${ }^{13-17}$ These studies have generally shown that use of an AP system may help to avoid hypoglycemia after an overestimated bolus in most subjects by predictively reducing or suspending insulin delivery as needed based on the glycemic trajectory, which would not occur during standard OL therapy. ${ }^{13,14}$ Similarly, AP systems may reduce the severity and duration of hyperglycemia experienced after an underestimated or missed meal bolus compared with standard OL therapy by increasing insulin delivery in response to elevated glucose levels. ${ }^{14-17}$ In addition to functioning safely with overestimated or missed boluses, it may be advantageous for an AP system to provide flexibility to users by safely allowing extended boluses for high-fat meals, ${ }^{18}$ which has not been studied previously.

The Omnipod Horizon ${ }^{\mathrm{TM}}$ Automated Glucose Control System is a single-hormone HCL system using a personalized model predictive control (MPC) algorithm under development. ${ }^{19,20}$ Initial feasibility studies have demonstrated that the MPC algorithm performed well and was safe in adult, adolescent, and pediatric subjects with type 1 diabetes. $^{20}$

The objective of this study was to evaluate the safety and performance of the Omnipod personalized MPC algorithm in adults with type 1 diabetes in a supervised outpatient hotel setting in response to overestimated and missed meal boluses, and extended boluses for high-fat meals.

\section{Materials and Methods}

\section{Study design}

This single-arm multicenter study assessed three specific meal announcement scenarios during a 54-h HCL period in a hotel setting: identical breakfast meals with bolus for $100 \%$ or $130 \%$ of the estimated CHO amount, identical lunch meals with or without a standard meal bolus, and identical high-fat dinners with standard or extended meal boluses, all occurring on sequential study days in nonrandomized order (Fig. 1). The extended bolus was delivered as $50 \%$ of the standard premeal bolus and the remaining 50\% delivered for the following $4 \mathrm{~h}$ (also known as a dual-wave or biphasic bolus). As a safety constraint, the remainder of the extended bolus was automatically cancelled if the MPC algorithm recommended suspension of insulin delivery based on the insulin on board and glucose trajectory.

The HCL study period was preceded by a 7-day outpatient OL run-in phase, during which subjects managed their diabetes at home per their usual routine using their personal insulin pump and a Dexcom G4 505 Share ${ }^{\circledR}$ AP sensor. Pump settings were adjusted as needed by the investigator, based upon their clinical judgment. The HCL study period began before breakfast on day 1 and ended $\sim 5 \mathrm{~h}$ after breakfast on day 3. Subjects selected meals from a variety of options containing 30-90 g CHO, and >30 g fat for the high-fat dinner, with the identical selected meal repeated for each of the three respective meal types (breakfast, lunch, and dinner). The standard meal bolus amount was calculated based on the $\mathrm{CHO}$ content estimated by the subject. A correction or reverse bolus based on a recent fingerstick blood glucose (BG) measurement could be given with the meal bolus at the discretion of the investigator or subject, to account for any difference in the starting BG that may have existed before the comparative meals. The guideline was to consider a correction bolus to a target of $140 \mathrm{mg} / \mathrm{dL}$ for a premeal fingerstick $\mathrm{BG}>140 \mathrm{mg} / \mathrm{dL}$ and a reverse correction to the study setpoint of $120 \mathrm{mg} / \mathrm{dL}$ for a premeal fingerstick BG $<100 \mathrm{mg} / \mathrm{dL}$. No sustained vigorous exercise was performed.

\section{Study participants}

Inclusion criteria for the study were age 18-65 years, type 1 diabetes for $\geq 1$ year, $\mathrm{HbAlc}$ value $>6 \%$ and $\leq 10 \%$ at screening, use of any insulin pump for $\geq 6$ months, and total daily dose (TDD) of insulin $\geq 0.3 \mathrm{U} / \mathrm{kg}$. Subjects with $\geq 1$

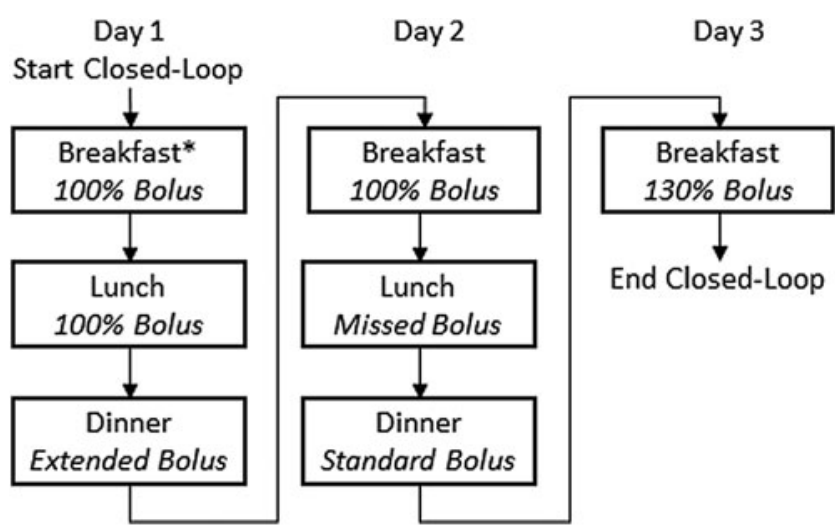

FIG. 1. Schematic diagram showing the order of meal scenarios studied for the three HCL study days. Meals were identical for each repeated meal type (breakfast, lunch, and dinner, respectively). *Breakfast on day 1 occurred immediately after HCL start-up and was not included in the meal scenario comparisons. HCL, hybrid closed-loop. 
episode of severe hypoglycemia or diabetic ketoacidosis requiring an emergency room visit or hospitalization within the past 6 months, or with hypoglycemia unawareness assessed by the Clarke Questionnaire, ${ }^{21}$ were excluded. Each study site received Institutional Review Board approval and subjects provided written informed consent (Clinicaltrials.gov registration NCT03064906).

\section{Safety and monitoring}

Study staff monitored subjects' status throughout the HCL study period, with hypoglycemia (fingerstick BG $<70 \mathrm{mg} / \mathrm{dL}$ or symptomatic) or severe hyperglycemia (fingerstick BG $\geq 300 \mathrm{mg} / \mathrm{dL}$ ) treated per standard practice. ${ }^{22} \mathrm{HCL}$ stopping criteria included unresolved symptomatic hypo- or hyperglycemia, subject request, loss of consciousness or seizure, or $\mathrm{BG} \geq 300 \mathrm{mg} / \mathrm{dL}$ and ketones $\geq 3.0 \mathrm{mmol} / \mathrm{L}$.

\section{Investigational device}

The investigational system used in this study, described previously by Buckingham et al., ${ }^{20}$ consisted of a modified version of the Omnipod insulin pump (Pod), a modified Personal Diabetes Manager, the Dexcom G4 505 Share AP System, and the personalized MPC algorithm running on a Windows 10 tablet configured with the portable AP system developed at the University of California at Santa Barbara. ${ }^{23}$ Inputs to the algorithm included the subjectspecific basal rate profile and TDD of insulin. The algorithm setpoint for this study was $120 \mathrm{mg} / \mathrm{dL}$.

\section{Outcomes}

The primary endpoints were safety parameters of percentage of time the sensor glucose was in a hypoglycemic range defined as $<70 \mathrm{mg} / \mathrm{dL}$ and hyperglycemic range defined as $\geq 250 \mathrm{mg} / \mathrm{dL}$ during the HCL study period. Secondary endpoints included mean sensor glucose, percentage time with sensor glucose $<54,<60,70-140,70-180,>180$, $\geq 300 \mathrm{mg} / \mathrm{dL}$, and standard deviation (SD) and coefficient of variation $(\mathrm{CV})$ of sensor glucose values. ${ }^{24,25}$ Outcomes for the three meal announcement scenarios were the 4-h postprandial glucose response to breakfast with $100 \%$ versus $130 \%$ of the standard meal bolus amount, the 4-h postprandial glucose response to lunch with and without a standard meal bolus, and the 12-h postprandial glucose response to a high-fat dinner with a standard or extended meal bolus.

\section{Statistical analysis}

As the primary endpoint for the study was safety, sample size was not determined by power calculation. Prespecified descriptive statistical analyses were performed for all subjects who entered the study $(n=12)$. Results were summarized for the 54-h HCL study period (overall) and the overnight period defined as 23:00 to 07:00 h. Results were also summarized for the three specific meal announcement scenarios. Outcomes were calculated per subject and summarized as mean $\pm \mathrm{SD}$ or median (interquartile range, IQR), unless otherwise indicated. Postprandial outcomes for each test case ( $130 \%$ overestimated meal bolus, missed meal bolus, or extended meal bolus) were compared with the standard meal bolus case for the corresponding identical meal using the two-tailed Wilcoxon signed rank test for paired obser- vations, with $P$-values $<0.05$ considered statistically significant. Statistical analyses were performed using SAS ${ }^{\circledR} 9.3$ or later (SAS Institute, Cary, NC) and MATLAB (MathWorks, Natick, MA).

\section{Results}

The characteristics of the 12 subjects are reported in Table 1. A summary of the pump setting adjustments for the 7-day OL run-in phase is included in the Supplementary Data (Supplementary Data are available online at http://www.liebertpub .com/dia).

\section{Glycemic outcomes}

The glycemic outcomes for the 54-h HCL study period overall, during daytime (07:00-23:00 h) and overnight (23:00-7:00 h), are shown in Table 2. The percentage of time with sensor glucose in the hypoglycemic range of $<70 \mathrm{mg} / \mathrm{dL}$ was median (IQR): $0.0 \%(0.0-1.2 \%)$ during the entire 54-h HCL period and $0.0 \%(0.0-0.0 \%)$ overnight. The percentage of time with sensor glucose in the hyperglycemic range of $\geq 250 \mathrm{mg} / \mathrm{dL}$ was mean $\pm \mathrm{SD} 4.5 \% \pm 3.6 \%$ for the overall HCL period and $1.2 \% \pm 4.1 \%$ overnight. The percentage of time with sensor glucose in the target range of 70-180 mg/dL was $76.1 \% \pm 8.0 \%$ overall and $92.7 \% \pm 13.3 \%$ overnight. The mean glucose was $153 \pm 15 \mathrm{mg} / \mathrm{dL}$ overall and $134 \pm 23 \mathrm{mg} / \mathrm{dL}$ overnight.

Additional study information, including a summary of the glycemic measures for the 7-day OL run-in phase (Table S1 and Figure S1), correction boluses given during HCL, and snack consumption unrelated to hypoglycemia, is included in the Supplementary Data.

\section{Meal challenges}

Overestimated bolus. The outcomes during the 4-h postprandial period after breakfast with $100 \%$ bolus or $130 \%$ overestimated bolus are shown in Figure 2 and Table 3. The estimated meal size was $49.4 \pm 8.7 \mathrm{~g} \mathrm{CHO}$ (range 34-60 g). The minimum sensor glucose for the 4-h postprandial period was $121 \pm 21 \mathrm{mg} / \mathrm{dL}$ for $100 \%$ bolus and $114 \pm 34 \mathrm{mg} / \mathrm{dL}$ for $130 \%$ bolus $(P=0.69)$. There was $0.0 \%(0.0-0.0 \%)$ of time $<70 \mathrm{mg} / \mathrm{dL}$ during the postprandial periods after both the $100 \%$ bolus and the $130 \%$ bolus $(P=0.50)$, with no subjects spending time $<70 \mathrm{mg} / \mathrm{dL}$ after the $100 \%$ bolus versus two subjects after the $130 \%$ bolus (Fig. 2). No subjects consumed

Table 1. Characteristics of the Study Population

\begin{tabular}{lc}
\hline Characteristic & Subjects $(\mathrm{n}=12)$ \\
\hline Age, years (range) & $35.4 \pm 14.1(20.3-60.6)$ \\
Female, \% & 75 \\
Diabetes duration, years (range) & $16.5 \pm 9.3(7.0-37.6)$ \\
Insulin pump use duration, & $12.0 \pm 8.6(1.6-28.2)$ \\
years (range) & \\
Insulin dose open-loop, $\mathrm{U} /(\mathrm{kg} \cdot \mathrm{d})^{\mathrm{a}}$ & $0.58 \pm 0.19$ \\
Insulin dose HCL, $\mathrm{U} /(\mathrm{kg} \cdot \mathrm{d})^{\mathrm{b}}$ & $0.56 \pm 0.18$ \\
$\mathrm{HbA} 1 \mathrm{c}, \%$ & $7.7 \pm 0.9$ \\
\hline
\end{tabular}

Results are mean \pm SD unless otherwise indicated.

${ }^{a}$ Insulin dose averaged for the 7-day open-loop run-in phase.

${ }^{\mathrm{b}}$ Insulin dose during entire HCL study period.

HCL, hybrid closed-loop; SD, standard deviation. 
Table 2. Glycemic Outcomes During the 54-Hour Hybrid Closed-Loop Period

\begin{tabular}{|c|c|c|c|}
\hline Parameter & Overall $(54-h)$ & Day $(07: 00-23: 00 h)$ & Night (23:00-7:00 h) \\
\hline Mean sensor glucose, $\mathrm{mg} / \mathrm{dL}$ & $153 \pm 15$ & $162 \pm 17$ & $134 \pm 23$ \\
\hline $\mathrm{SD}, \mathrm{mg} / \mathrm{dL}$ & $45 \pm 6$ & $48 \pm 8$ & $22 \pm 12$ \\
\hline Coefficient of variation, $\%$ & $29.6 \pm 4.3$ & $29.6 \pm 5.2$ & $16.1 \pm 7.0$ \\
\hline \multicolumn{4}{|c|}{ Percentage time in glucose range, $\%$} \\
\hline \multirow[t]{2}{*}{$<54 \mathrm{mg} / \mathrm{dL}$} & $0.1 \pm 0.2$ & $0.1 \pm 0.3$ & $0.0 \pm 0.0$ \\
\hline & $0.0(0.0-0.0)$ & $0.0(0.0-0.0)$ & $0.0(0.0-0.0)$ \\
\hline \multirow[t]{2}{*}{$<60 \mathrm{mg} / \mathrm{dL}$} & $0.1 \pm 0.3$ & $0.2 \pm 0.4$ & $0.0 \pm 0.0$ \\
\hline & $0.0(0.0-0.1)$ & $0.0(0.0-0.1)$ & $0.0(0.0-0.0)$ \\
\hline \multirow[t]{2}{*}{$<70 \mathrm{mg} / \mathrm{dL}$} & $0.6 \pm 0.9$ & $0.8 \pm 1.3$ & $0.2 \pm 0.6$ \\
\hline & $0.0(0.0-1.2)$ & $0.0(0.0-1.3)$ & $0.0(0.0-0.0)$ \\
\hline $70-140 \mathrm{mg} / \mathrm{dL}$ & $46.4 \pm 14.5$ & $36.1 \pm 13.6$ & $68.9 \pm 29.3$ \\
\hline $70-180 \mathrm{mg} / \mathrm{dL}$ & $76.1 \pm 8.0$ & $68.6 \pm 9.9$ & $92.7 \pm 13.3$ \\
\hline$>180 \mathrm{mg} / \mathrm{dL}$ & $23.3 \pm 8.5$ & $30.6 \pm 10.8$ & $7.1 \pm 13.4$ \\
\hline$\geq 250 \mathrm{mg} / \mathrm{dL}$ & $4.5 \pm 3.6$ & $6.0 \pm 4.5$ & $1.2 \pm 4.1$ \\
\hline$\geq 300 \mathrm{mg} / \mathrm{dL}$ & $0.9 \pm 1.1$ & $1.3 \pm 1.6$ & $0.0 \pm 0.2$ \\
\hline
\end{tabular}

Results are sensor glucose values, mean \pm SD or median (IQR) unless otherwise indicated; SI conversion factor to convert glucose to $\mathrm{mmol} / \mathrm{L}$, multiply by 0.0555 .

IQR, interquartile range; SI, International System of Units.

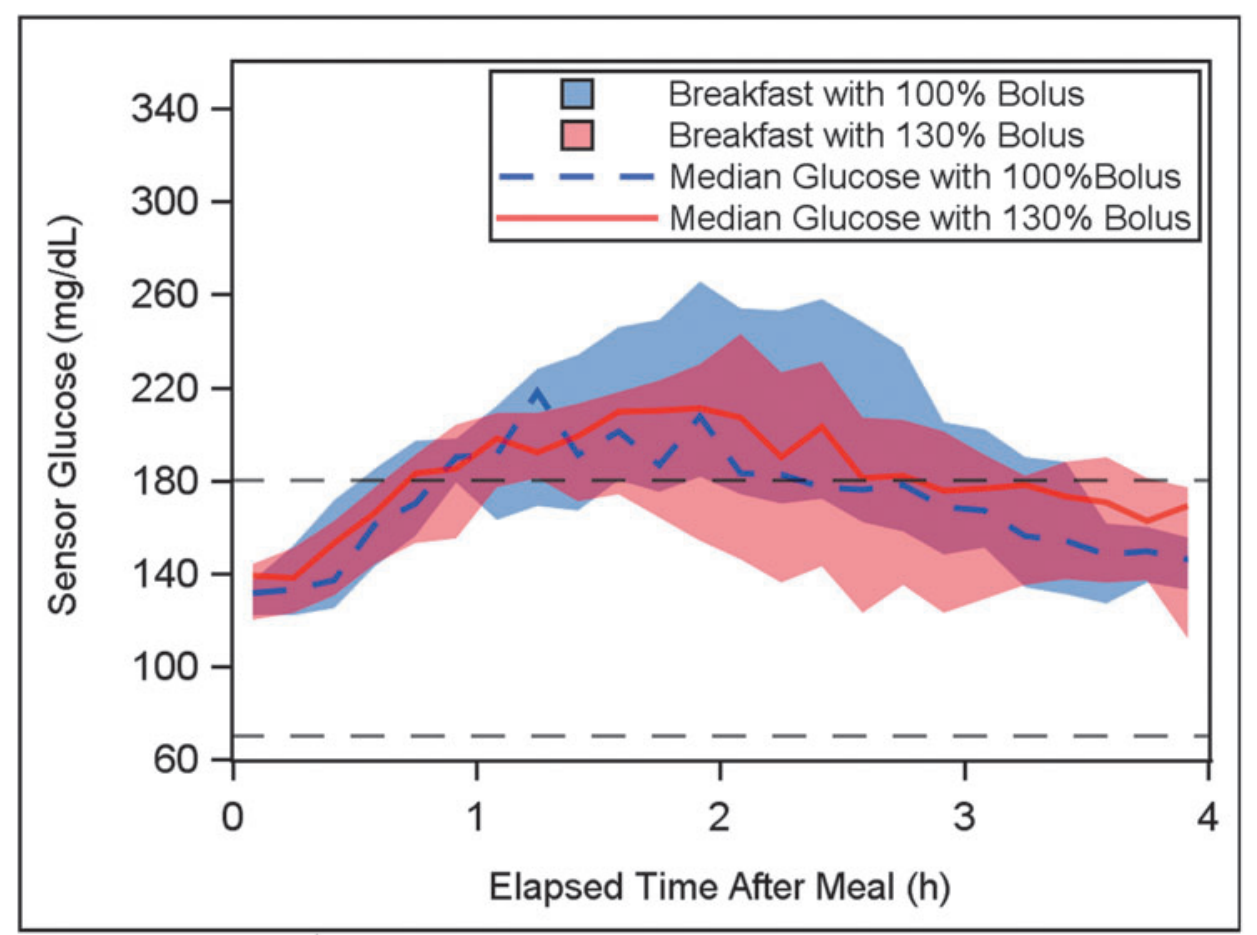

Percent of Subjects in Glycemic Ranges by Elapsed Time After Meal (h)

\begin{tabular}{|c|c|c|c|c|c|c|c|c|}
\hline & \multicolumn{2}{|c|}{0 to 1 Hours } & \multicolumn{2}{|c|}{1 to 2 Hours } & \multicolumn{2}{|c|}{2 to 3 Hours } & \multicolumn{2}{|c|}{3 to 4 Hours } \\
\hline $\begin{array}{c}\text { CGM } \\
\text { (mg/dL) }\end{array}$ & $100 \%$ & $130 \%$ & $100 \%$ & $130 \%$ & $100 \%$ & $130 \%$ & $100 \%$ & $130 \%$ \\
\hline$<54$ & $0.0 \%$ & $0.0 \%$ & $0.0 \%$ & $0.0 \%$ & $0.0 \%$ & $8.3 \%$ & $0.0 \%$ & $0.0 \%$ \\
\hline$<70$ & $0.0 \%$ & $0.0 \%$ & $0.0 \%$ & $8.3 \%$ & $0.0 \%$ & $8.3 \%$ & $0.0 \%$ & $16.7 \%$ \\
\hline$>180$ & $66.7 \%$ & $58.3 \%$ & $91.7 \%$ & $75.0 \%$ & $75.0 \%$ & $66.7 \%$ & $33.3 \%$ & $58.3 \%$ \\
\hline$\geq 250$ & $8.3 \%$ & $8.3 \%$ & $41.7 \%$ & $8.3 \%$ & $33.3 \%$ & $25.0 \%$ & $8.3 \%$ & $0.0 \%$ \\
\hline
\end{tabular}

FIG. 2. Comparison of glycemic response with a standard 100\% meal bolus versus a 130\% overestimated bolus for a 4-h postprandial period. Median sensor glucose response is plotted for the 12 subjects for $4 \mathrm{~h}$ after a $34-60 \mathrm{~g}$ CHO breakfast with standard meal bolus ( $100 \%$ of calculated value, dashed blue line) and overestimated meal bolus (130\% of calculated value, solid red line). Each subject consumed an identical meal on the days with $100 \%$ and $130 \%$ meal bolus. The shaded area represents the IQR. The target range of $70-180 \mathrm{mg} / \mathrm{dL}$ is indicated by black dashed lines. The percentage of subjects in various glycemic ranges (hypoglycemia $<70$ and $<54 \mathrm{mg} / \mathrm{dL}$, and hyperglycemia $>180$ and $\geq 250 \mathrm{mg} / \mathrm{dL}$ ) during each hour of the postprandial period is tabulated for each bolus type (100\% and 130\%) beneath the graph. CHO, carbohydrate; IQR, interquartile range. 
Table 3. Preprandial and 4-Hour Postprandial

Outcomes FOR BREAKFast With STANDARD 100\% Versus $130 \%$ Overestimated Meal Bolus

\begin{tabular}{|c|c|c|c|}
\hline & \multicolumn{2}{|c|}{ Bolus type } & \multirow[b]{2}{*}{$\mathrm{P}$} \\
\hline & $100 \%$ Bolus & $130 \%$ Bolus & \\
\hline \multicolumn{4}{|l|}{ Glucose values, mg/dL } \\
\hline Preprandial & $126 \pm 13^{\mathrm{a}}$ & $132 \pm 13$ & 0.21 \\
\hline Postprandial peak ${ }^{\mathrm{b}}$ & $229 \pm 47^{\mathrm{a}}$ & $219 \pm 47$ & 0.35 \\
\hline Excursion $^{\mathrm{c}}$ & $103 \pm 49^{a}$ & $88 \pm 47$ & 0.21 \\
\hline Maximum $^{\mathrm{d}}$ & $242 \pm 64$ & $222 \pm 44$ & 0.27 \\
\hline Minimum & $121 \pm 21$ & $114 \pm 34$ & 0.69 \\
\hline Mean & $182 \pm 35$ & $171 \pm 34$ & 0.30 \\
\hline \multirow[t]{2}{*}{$\mathrm{AUC},{ }^{\mathrm{e}} \mathrm{h} \cdot(\mathrm{mg} / \mathrm{dL})$} & $230 \pm 139$ & $177 \pm 97$ & 0.13 \\
\hline & $182(137-318)$ & $172(101-263)$ & \\
\hline \multicolumn{4}{|c|}{ Percentage time in glucose range, $\%$} \\
\hline \multirow[t]{2}{*}{$<54 \mathrm{mg} / \mathrm{dL}$} & $0.0 \pm 0.0$ & $0.4 \pm 1.3$ & 1.0 \\
\hline & $0.0(0.0-0.0)$ & $0.0(0.0-0.0)$ & \\
\hline \multirow[t]{2}{*}{$<70 \mathrm{mg} / \mathrm{dL}$} & $0 \pm 0$ & $2.4 \pm 5.7$ & 0.50 \\
\hline & $0.0(0.0-0.0)$ & $0.0(0.0-0.0)$ & \\
\hline$>180 \mathrm{mg} / \mathrm{dL}$ & $40.3 \pm 28.3$ & $43.5 \pm 27.4$ & 0.97 \\
\hline$\geq 250 \mathrm{mg} / \mathrm{dL}$ & $12.5 \pm 18.9$ & $4.0 \pm 9.2$ & 0.16 \\
\hline \multicolumn{4}{|l|}{ Insulin delivery, $\mathrm{U}$} \\
\hline Preprandial bolus & $5.1 \pm 2.1$ & $6.7 \pm 2.7$ & - \\
\hline $\begin{array}{l}\text { Postprandial } \\
\text { algorithm delivery }\end{array}$ & $4.3 \pm 1.7$ & $3.9 \pm 1.7$ & 0.4 \\
\hline $\begin{array}{l}\text { Total preprandial+ } \\
\text { postprandial }\end{array}$ & $9.3 \pm 2.3$ & $10.6 \pm 3.0$ & - \\
\hline \multicolumn{4}{|c|}{ Number of subjects consuming supplemental $\mathrm{CHO}$} \\
\hline Total & 0 & 3 & - \\
\hline $\begin{array}{l}\text { With fingerstick } \\
\text { BG <70 mg/dL }\end{array}$ & 0 & 2 & \\
\hline
\end{tabular}

Results are sensor glucose values, mean $\pm \mathrm{SD}$ or median (IQR) unless otherwise indicated; SI conversion factor to convert glucose to $\mathrm{mmol} / \mathrm{L}$, multiply by 0.0555 .

${ }^{\mathrm{a}} N=11$ due to missing sensor data for one subject.

${ }^{\mathrm{b}}$ Primary peak identified as resulting from meal.

${ }^{c}$ Postprandial peak minus preprandial glucose.

${ }^{\mathrm{d}}$ Maximum sensor glucose for postprandial period.

${ }^{\mathrm{e}}$ Incremental AUC that is more than the premeal concentration level.

$* P<0.05$.

AUC, area under the glucose concentration curve; BG, blood glucose; $\mathrm{CHO}$, carbohydrate.

supplemental $\mathrm{CHO}$ during the postprandial period after the $100 \%$ bolus and three subjects consumed supplemental $\mathrm{CHO}$ (two with fingerstick BG $<70 \mathrm{mg} / \mathrm{dL}$ ) after the $130 \%$ bolus. The percentage time with sensor glucose $\geq 250 \mathrm{mg} / \mathrm{dL}$ in the 4-h period after breakfast was lower with the $130 \%$ overestimated bolus $(12.5 \% \pm 18.9 \%$ and $4.0 \% \pm 9.2 \%$ for the $100 \%$ and $130 \%$ boluses, respectively, corresponding to $30 \pm 45 \mathrm{~min}$ and $10 \pm 22 \mathrm{~min}$, although the difference was not significant $[P=0.16])$.

Missed bolus. The outcomes during the 4-h postprandial period after lunch with a standard $100 \%$ or missed meal bolus are shown in Figure 3 and Table 4. The estimated meal size was $48.1 \pm 12.4 \mathrm{~g} \mathrm{CHO}$ (range $30-65 \mathrm{~g}$ ). The peak postprandial sensor glucose was $180 \pm 45 \mathrm{mg} / \mathrm{dL}$ after the $100 \%$ bolus and $243 \pm 43 \mathrm{mg} / \mathrm{dL}$ after the missed bolus (a 35\% increase, $P=0.001$ ). After the $100 \%$ bolus, the six subjects whose sensor glucose rose $>180 \mathrm{mg} / \mathrm{dL}$ returned less than this threshold within $2.8 \pm 2.3 \mathrm{~h}$ of the meal. After the missed bolus, the 11 subjects whose sensor glucose rose $>180 \mathrm{mg} / \mathrm{dL}$ returned less than this threshold within $3.8 \pm 1.3 \mathrm{~h}$ of the meal. The mean glucose level during the 4-h postprandial period was $141 \pm 31 \mathrm{mg} / \mathrm{dL}$ after the $100 \%$ bolus and $192 \pm 32 \mathrm{mg} / \mathrm{dL}$ after the missed bolus $(P=0.001)$. There was $0.0 \%(0.0-0.0 \%)$ of time $<70 \mathrm{mg} / \mathrm{dL}$ during the postprandial periods after lunch with both the $100 \%$ bolus and the missed bolus $(P=0.5)$. The percentage time with sensor glucose $\geq 250 \mathrm{mg} / \mathrm{dL}$ in the 4-h period after lunch was lower with the $100 \%$ bolus $(0.2 \% \pm 0.6 \%$ and $10.3 \% \pm 16.5 \%$ for the $100 \%$ and missed boluses, respectively, corresponding to $0.5 \pm 1 \mathrm{~min}$ and $25 \pm$ 40 min $[P=0.06])$. Four subjects consumed supplemental $\mathrm{CHO}$ (two with fingerstick $\mathrm{BG}<70 \mathrm{mg} / \mathrm{dL}$ ) in the $100 \%$ bolus case, versus one subject (no fingerstick BG $<70 \mathrm{mg} / \mathrm{dL}$ ) in the missed bolus case.

Extended bolus. The outcomes during the 12-h postprandial period after the high-fat dinner with a standard $100 \%$ or an extended meal bolus are shown in Figure 4 and Table 5. The estimated meal size was $66.5 \pm 20.9 \mathrm{~g} \mathrm{CHO}$ (range 36-90 g) and $40.3 \pm 9.3 \mathrm{~g}$ fat (range $30-58 \mathrm{~g}$ ). The data are stratified by subjects who received the extended bolus for $>1 \mathrm{~h}[n=5$, duration of extended bolus median $3.9 \mathrm{~h}$ (range 1.8-4h)] and subjects who had the extended portion of the bolus canceled by the algorithm within $1 \mathrm{~h}[n=7$, duration of extended bolus median 10 min (range 10-20 min)] according to the algorithm safety constraint.

Subjects who received the extended bolus for $>1 \mathrm{~h}(n=5)$ had a mean preprandial sensor glucose more than the setpoint of $120 \mathrm{mg} / \mathrm{dL}$ before receiving the extended bolus (preprandial glucose $164 \pm 29 \mathrm{mg} / \mathrm{dL}$ for standard bolus and $134 \pm 14 \mathrm{mg} / \mathrm{dL}$ for extended bolus). The maximum sensor glucose in the 12-h postprandial period after dinner was $224 \pm 53 \mathrm{mg} / \mathrm{dL}$ with standard bolus and $228 \pm 56 \mathrm{mg} / \mathrm{dL}$ with extended bolus (a $2 \%$ difference, $P=0.81$ ). The minimum sensor glucose during the postprandial period was $100 \pm 20 \mathrm{mg} /$ $\mathrm{dL}$ (range 74-126 mg/dL) with standard bolus and $107 \pm 11$ $\mathrm{mg} / \mathrm{dL}$ (range $92-122 \mathrm{mg} / \mathrm{dL}$ ) with extended bolus $(P=0.31)$. There was no time spent $<70 \mathrm{mg} / \mathrm{dL}$ during the postprandial period, and a similar percentage of time $\geq 250 \mathrm{mg} / \mathrm{dL}$ : $5.6 \% \pm 12.5 \%(40 \pm 90 \mathrm{~min})$ and $4.4 \% \pm 6.1 \%(32 \pm 44 \mathrm{~min})$ of time for standard and extended boluses, respectively $(P=1.0)$. No subjects consumed supplemental $\mathrm{CHO}$ during the postprandial period for either bolus type.

Subjects who had the extended bolus canceled within $1 \mathrm{~h}$ $(n=7)$ had a mean preprandial sensor glucose less than the setpoint of $120 \mathrm{mg} / \mathrm{dL}$ before receiving the extended bolus (preprandial glucose $125 \pm 38 \mathrm{mg} / \mathrm{dL}$ for standard bolus and $106 \pm 20 \mathrm{mg} / \mathrm{dL}$ for extended bolus). The maximum sensor glucose during the 12-h postprandial period after dinner was $174 \pm 29 \mathrm{mg} / \mathrm{dL}$ with standard bolus and $201 \pm 23 \mathrm{mg} / \mathrm{dL}$ with extended bolus (a 16\% difference, $P=0.08$ ). The minimum sensor glucose during the postprandial period was $82 \pm 23 \mathrm{mg} / \mathrm{dL}$ (range $46-108 \mathrm{mg} / \mathrm{dL}$ ) with standard bolus and $84 \pm 17 \mathrm{mg} / \mathrm{dL}$ (range $65-102 \mathrm{mg} / \mathrm{dL}$ ) with extended bolus $(P=0.89)$. There was no time spent $\geq 250 \mathrm{mg} / \mathrm{dL}$ during the postprandial period, with $0.0 \%(0.0-3.5 \%)$ [0 $\min (0-25$ $\mathrm{min})]$ and $0.0 \%(0.0-0.7 \%)[0 \mathrm{~min}(0-5 \mathrm{~min})]$ of time $<70 \mathrm{mg} /$ $\mathrm{dL}$ for standard and extended boluses, respectively $(P=0.75)$. Three subjects consumed supplemental $\mathrm{CHO}$ (two with 


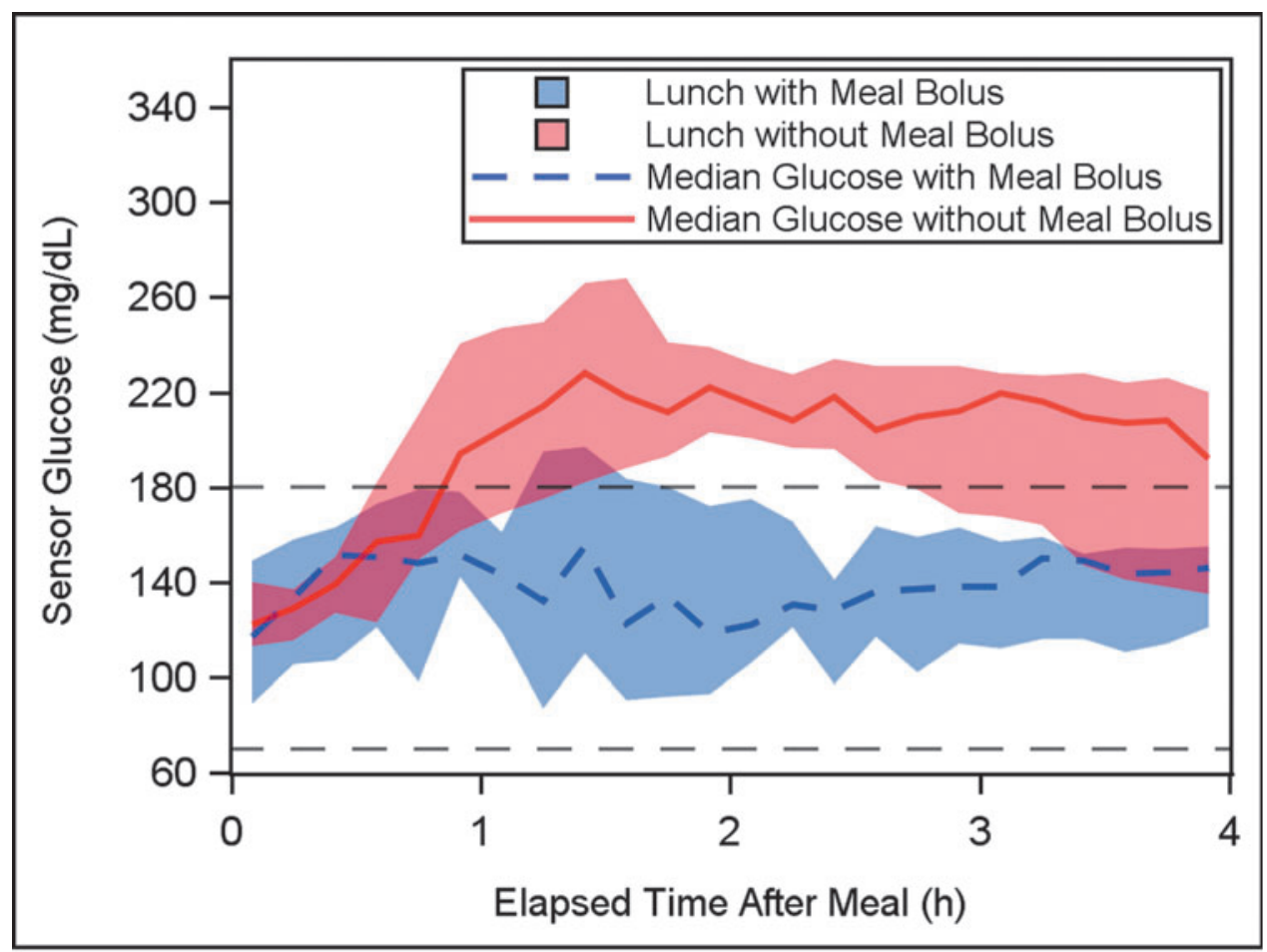

Percent of Subjects in Glycemic Ranges by Elapsed Time After Meal (h)

\begin{tabular}{|c|c|c|c|c|c|c|c|c|}
\hline & \multicolumn{2}{|c|}{0 to 1 Hours } & \multicolumn{2}{c|}{1 to 2 Hours } & \multicolumn{2}{c|}{2 to 3 Hours } & \multicolumn{2}{c|}{3 to 4 Hours } \\
\hline $\begin{array}{c}\text { CGM } \\
\text { (mg/dL) }\end{array}$ & $\begin{array}{c}100 \% \\
\text { Bolus }\end{array}$ & $\begin{array}{c}\text { Missed } \\
\text { Bolus }\end{array}$ & $\begin{array}{c}100 \% \\
\text { Bolus }\end{array}$ & $\begin{array}{c}\text { Missed } \\
\text { Bolus }\end{array}$ & $\begin{array}{c}100 \% \\
\text { Bolus }\end{array}$ & $\begin{array}{c}\text { Missed } \\
\text { Bolus }\end{array}$ & $\begin{array}{c}100 \% \\
\text { Bolus }\end{array}$ & $\begin{array}{c}\text { Missed } \\
\text { Bolus }\end{array}$ \\
\hline$<54$ & $0.0 \%$ & $0.0 \%$ & $0.0 \%$ & $0.0 \%$ & $0.0 \%$ & $0.0 \%$ & $0.0 \%$ & $0.0 \%$ \\
\hline$<70$ & $0.0 \%$ & $0.0 \%$ & $16.7 \%$ & $0.0 \%$ & $0.0 \%$ & $0.0 \%$ & $0.0 \%$ & $0.0 \%$ \\
\hline$>180$ & $33.3 \%$ & $50.0 \%$ & $33.3 \%$ & $91.7 \%$ & $25.0 \%$ & $91.7 \%$ & $16.7 \%$ & $66.7 \%$ \\
\hline$\geq 250$ & $8.3 \%$ & $8.3 \%$ & $0.0 \%$ & $33.3 \%$ & $0.0 \%$ & $16.7 \%$ & $0.0 \%$ & $8.3 \%$ \\
\hline
\end{tabular}

FIG. 3. Comparison of glycemic response with a standard $100 \%$ meal bolus versus a missed bolus for a 4-h postprandial period. Median sensor glucose response is plotted for the 12 subjects for $4 \mathrm{~h}$ after a 30-65 $\mathrm{g}$ CHO lunch with (dashed blue line) and without (solid red line) a meal bolus. Each subject consumed an identical meal on the days with and without the meal bolus. The shaded area represents the IQR. The target range of $70-180 \mathrm{mg} / \mathrm{dL}$ is indicated by black dashed lines. The percentage of subjects in various glycemic ranges (hypoglycemia $<70$ and $<54 \mathrm{mg} / \mathrm{dL}$, and hyperglycemia $>180$ and $\geq 250 \mathrm{mg}$ / $\mathrm{dL}$ ) during each hour of the postprandial period is tabulated for each bolus type (100\% and missed) beneath the graph.

fingerstick $\mathrm{BG}<70 \mathrm{mg} / \mathrm{dL}$ ) for the standard bolus case, versus two subjects (zero with fingerstick $B G<70 \mathrm{mg} / \mathrm{dL}$ ) for the extended bolus case.

\section{Safety outcomes}

There were no serious adverse events reported, and the HCL period was completed for all 12 subjects with no instances of the stopping criteria being met. In the 648 subjecthours of HCL use, there were 5 hyperglycemic events in 5 subjects involving meter glucose values $\geq 300 \mathrm{mg} / \mathrm{dL}$, of which 3 required treatment. One of these events resulted in a Pod change due to suspected infusion site failure. There were 9 hypoglycemic events in 5 subjects involving meter glucose values $<70 \mathrm{mg} / \mathrm{dL}$, with 10 oral $\mathrm{CHO}$ treatments given (10$16 \mathrm{~g} \mathrm{CHO})$.

\section{Percentage time in $\mathrm{HCL}$}

The mean percentage of the total HCL study period spent with the system running in closed-loop was $99.2 \% \pm 2.3 \%$ (range: 92.2\%-100.0\%). There was one suspected infusion site failure and one Pod occlusion alarm during the HCL period, each resulting in Pod replacement and correction bolus. The causes for interruption of closed-loop included sensor or Pod replacement, temporary loss of Pod or CGM communication, or loss of system battery charge.

\section{Discussion}

This multicenter feasibility study demonstrated that the Omnipod personalized MPC algorithm performed well and was safe during day and night use for $54 \mathrm{~h}$ in adults with type 1 diabetes in a supervised hotel setting. In addition, the robust multiday design with repeated identical meals allowed examination of the MPC algorithm response to a standard 100\% bolus compared with the test cases of a $130 \%$ overestimated bolus, a missed bolus, or an extended bolus. Repeating identical meals on subsequent days and excluding strenuous physical activity during the HCL period removed potentially confounding factors to isolate the effect of the various meal 
Table 4. Preprandial and 4-Hour Postprandial OutCOMES FOR LUNCH WITH STANDARD 100\% Versus Missed Meal Bolus

\begin{tabular}{|c|c|c|c|}
\hline & \multicolumn{2}{|c|}{ Bolus type } & \multirow[b]{2}{*}{$\mathrm{P}$} \\
\hline & $100 \%$ Bolus $^{\mathrm{a}}$ & No bolus & \\
\hline \multicolumn{4}{|l|}{ Glucose values, mg/dL } \\
\hline Preprandial & $117 \pm 41$ & $130 \pm 19$ & 0.18 \\
\hline Postprandial peak ${ }^{\mathrm{b}}$ & $180 \pm 45$ & $243 \pm 43$ & $0.001 *$ \\
\hline Excursion $^{\mathrm{c}}$ & $63 \pm 46$ & $114 \pm 47$ & $0.01 *$ \\
\hline Maximum $^{\mathrm{d}}$ & $188 \pm 37$ & $245 \pm 43$ & $0.002 *$ \\
\hline Minimum & $98 \pm 29$ & $118 \pm 18$ & $0.02 *$ \\
\hline Mean & $141 \pm 31$ & $192 \pm 32$ & $0.001 *$ \\
\hline \multirow{2}{*}{$\mathrm{AUC},{ }^{\mathrm{e}} \mathrm{h} \cdot(\mathrm{mg} / \mathrm{dL})$} & $136 \pm 99$ & $255 \pm 132$ & $0.03 *$ \\
\hline & $133(26-193)$ & $253(166-362)$ & \\
\hline \multicolumn{4}{|c|}{ Percentage time in glucose range, $\%$} \\
\hline \multirow[t]{2}{*}{$<54 \mathrm{mg} / \mathrm{dL}$} & $0.0 \pm 0.0$ & $0.0 \pm 0.0$ & - \\
\hline & $0.0(0.0-0.0)$ & $0.0(0.0-0.0)$ & \\
\hline \multirow[t]{2}{*}{$<70 \mathrm{mg} / \mathrm{dL}$} & $1.6 \pm 4.0$ & $0 \pm 0$ & 0.5 \\
\hline & $0.0(0.0-0.0)$ & $0.0(0.0-0.0)$ & \\
\hline$>180 \mathrm{mg} / \mathrm{dL}$ & $18.4 \pm 20.8$ & $59.4 \pm 25.2$ & $0.002 *$ \\
\hline$\geq 250 \mathrm{mg} / \mathrm{dL}$ & $0.2 \pm 0.6$ & $10.3 \pm 16.5$ & 0.06 \\
\hline \multicolumn{4}{|l|}{ Insulin delivery, $\mathrm{U}$} \\
\hline Preprandial bolus & $5.2 \pm 2.5$ & - & - \\
\hline $\begin{array}{l}\text { Postprandial } \\
\text { algorithm } \\
\text { delivery }\end{array}$ & $3.7 \pm 1.9$ & $6.6 \pm 2.2$ & $<0.001 *$ \\
\hline $\begin{array}{l}\text { Total preprandial+ } \\
\text { postprandial }\end{array}$ & $8.9 \pm 3.4$ & $6.6 \pm 2.2$ & - \\
\hline \multicolumn{4}{|c|}{ Number of subjects consuming supplemental $\mathrm{CHO}$} \\
\hline Total & 4 & 1 & - \\
\hline $\begin{array}{l}\text { With fingerstick } \\
\text { BG }<70 \mathrm{mg} / \mathrm{dL}\end{array}$ & 2 & 0 & - \\
\hline
\end{tabular}

Results are sensor glucose values, mean \pm SD unless otherwise indicated; SI conversion factor to convert glucose to $\mathrm{mmol} / \mathrm{L}$, multiply by 0.0555 .

${ }^{a} N=11$, one subject excluded due to meal size deviation for $100 \%$ bolus case.

${ }^{\mathrm{b}}$ Primary peak identified as resulting from meal.

${ }^{c}$ Postprandial peak minus preprandial glucose, note that this value was negative for two subjects in the $100 \%$ bolus case.

${ }^{\mathrm{d}}$ Maximum sensor glucose for postprandial period.

e Incremental AUC that is more than the premeal concentration level.

$* P<0.05$.

bolus scenarios. The study design challenged the HCL algorithm to demonstrate appropriate responsiveness to the glycemic trajectory to minimize hypoglycemia in response to an overestimated meal bolus, as well as prevent prolonged hyperglycemia in response to a missed meal bolus, which are both common scenarios expected to occur in real-world use of the device. The feasibility of extended bolus use for highfat meals during HCL was also evaluated. Overall, the results show that the algorithm was safe in the presence of each of these three meal bolus scenarios.

In the case of an overestimated meal bolus, the primary concern is subsequent hypoglycemia during the postprandial period. In this study, postprandial hypoglycemia $<70 \mathrm{mg} / \mathrm{dL}$ was avoided for $83 \%(10 / 12)$ of subjects after the $130 \%$ overestimated bolus, with a median of $0 \%$ of time $<70 \mathrm{mg} / \mathrm{dL}$ for $4 \mathrm{~h}$ and three subjects consuming supplemental $\mathrm{CHO}$ (two with fingerstick $B G<70 \mathrm{mg} / \mathrm{dL}$ ). Attenuation of insulin delivery for impending late postprandial hypoglycemia allows reduction of the duration and severity of hypoglycemia that would otherwise be experienced in similar OL scenarios. Our results support the robust performance of the algorithm in cases of overestimated meal boluses. Similar results were reported by Chase et al. examining the response of a singlehormone AP system to a $130 \%$ overestimated meal bolus for a $63 \mathrm{~g} \mathrm{CHO}(51-75 \mathrm{~g})$ meal in 40 adults and adolescents with type 1 diabetes: a median of $0 \%$ of plasma glucose values $\leq 70 \mathrm{mg} / \mathrm{dL}$ was reported during the $4 \mathrm{~h}$ after the overestimated bolus. Two subjects had BG values $<70 \mathrm{mg} / \mathrm{dL}$, and there were one hypoglycemic treatment intervention and eight $\mathrm{CHO}$ treatments for predicted low glucose during the 4$\mathrm{h}$ postprandial period. ${ }^{14}$

Gingras et al. also reported similar results in a study of a dual-hormone AP system in 20 adult subjects with a meal bolus overestimated by $27 \%$ ( $75 \mathrm{~g} \mathrm{CHO}$ meal, $n=10$ ) or $44 \%$ ( $45 \mathrm{~g} \mathrm{CHO}$ meal, $n=10$ ): median of $0 \%$ of time spent $<72 \mathrm{mg} / \mathrm{dL}$ during the $4 \mathrm{~h}$ postprandial period with a total of three episodes of hypoglycemia treated with $\mathrm{CHO}$. Total glucagon delivery (microboluses) was similar in the standard and overestimated bolus cases during the postprandial period, although most of the glucagon was delivered later in the postprandial period with overestimated boluses. ${ }^{13}$ Results of these and the present study show that in response to an overestimated bolus, an AP system may in many cases be able to avoid hypoglycemia occurrence or reduce its severity by attenuating postprandial insulin delivery; however, treatment with fast-acting $\mathrm{CHO}$ is still necessary in some cases, even with systems that have automated glucagon delivery.

In the case of a missed meal bolus, the results of this study compared favorably with other recent reports. ${ }^{14,15}$ Chase et al. examined the response of an AP system to a missed meal bolus for a $50 \mathrm{~g}$ CHO meal. The present study was able to achieve less postprandial hyperglycemia after a missed bolus, with a median excursion from baseline to peak of $112 \mathrm{mg} / \mathrm{dL}$ (mean $114 \mathrm{mg} / \mathrm{dL}$ ), compared with a median of $156 \mathrm{mg} / \mathrm{dL}$ in Chase et al. (mean not reported). ${ }^{14}$ Cherñavvsky et al. studied the effect of a missed bolus for a $30 \mathrm{~g}$ CHO snack and underestimated $(75 \%)$ bolus for an $80 \mathrm{~g} \mathrm{CHO}$ lunch with a single-hormone AP system in 16 adolescents. The results were $20.7 \%$ and $28.2 \%$ of time $>250 \mathrm{mg} / \mathrm{dL}$ during the $4-\mathrm{h}$ postprandial period for the missed snack bolus and reduced lunch bolus, respectively. ${ }^{15}$ The present study demonstrated a lower percentage of time in hyperglycemia $\geq 250 \mathrm{mg} / \mathrm{dL}$ during the postprandial period after a missed meal bolus $(10.3 \%) .{ }^{15}$ The differences in outcomes may be attributed to a number of factors including different control algorithm, meal size, or population. Forlenza et al. included both announced and unannounced meals in their recent closed-loop study of 10 adults and adolescents, with an average of $75 \mathrm{~g}$ and $95 \mathrm{~g}$ $\mathrm{CHO}$ for announced and unannounced meals, respectively. ${ }^{17}$ Similar to the present study, mean CGM was lower for announced than for unannounced meals $(141 \mathrm{mg} / \mathrm{dL}$ vs. $198 \mathrm{mg} /$ $\mathrm{dL}$, respectively), with $2.2 \%$ of time $>250 \mathrm{mg} / \mathrm{dL}$ after the announced meals versus $23 \%$ of time after the unannounced meals.

Owing to the characteristics of currently available insulins, it may be inevitable that increased hyperglycemia will be experienced with a missed bolus; however, an AP 


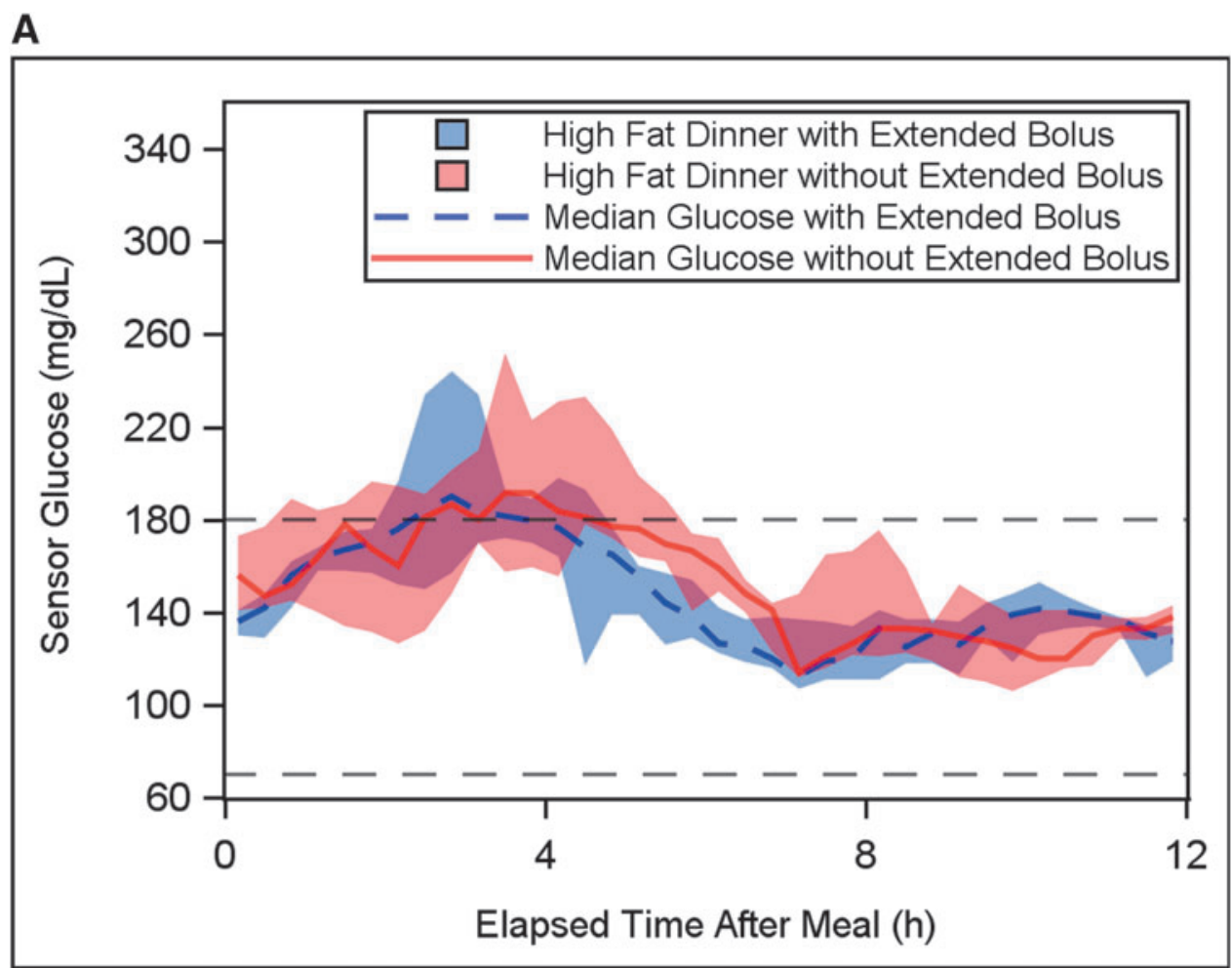

Percent of Subjects in Glycemic Ranges by Elapsed Time After Meal (h)

\begin{tabular}{|c|c|c|c|c|c|c|}
\hline & \multicolumn{2}{|c|}{0 to 4 Hours } & \multicolumn{2}{c|}{4 to 8 Hours } & \multicolumn{2}{c|}{8 to 12 Hours } \\
\hline $\begin{array}{c}\text { CGM } \\
(\mathrm{mg} / \mathrm{dL})\end{array}$ & $\begin{array}{c}\text { Extended } \\
\text { Bolus }\end{array}$ & $\begin{array}{c}\text { Standard } \\
\text { Bolus }\end{array}$ & $\begin{array}{c}\text { Extended } \\
\text { Bolus }\end{array}$ & $\begin{array}{c}\text { Standard } \\
\text { Bolus }\end{array}$ & $\begin{array}{c}\text { Extended } \\
\text { Bolus }\end{array}$ & $\begin{array}{c}\text { Standard } \\
\text { Bolus }\end{array}$ \\
\hline$<54$ & $0.0 \%$ & $0.0 \%$ & $0.0 \%$ & $0.0 \%$ & $0.0 \%$ & $0.0 \%$ \\
\hline$<70$ & $0.0 \%$ & $0.0 \%$ & $0.0 \%$ & $0.0 \%$ & $0.0 \%$ & $0.0 \%$ \\
\hline$>180$ & $80.0 \%$ & $80.0 \%$ & $40.0 \%$ & $80.0 \%$ & $0.0 \%$ & $20.0 \%$ \\
\hline$\geq 250$ & $40.0 \%$ & $20.0 \%$ & $20.0 \%$ & $20.0 \%$ & $0.0 \%$ & $0.0 \%$ \\
\hline
\end{tabular}

FIG. 4A. (Continued)

system is expected to reduce the severity and duration of hyperglycemia as compared with what would be observed with a missed bolus in OL therapy. Although this study did not include a comparison with OL therapy with missed bolus, Cherñavvsky et al. demonstrated the benefit of an AP by showing that the percentage of time $>250 \mathrm{mg} / \mathrm{dL}$ during the 4-h postprandial period with AP was reduced twofold from OL therapy under the same meal bolus challenge scenarios $(40.3 \%$ and $58.5 \%$ of time $>250 \mathrm{mg} / \mathrm{dL}$ for missed and reduced boluses during standard care, respectively). ${ }^{15}$ Such a reduction in hyperglycemia with AP use may improve long-term outcomes for patients who sometimes miss meal boluses.

To our knowledge, this study was the first to evaluate an extended bolus as part of an AP system. An extended bolus gives users the flexibility to deliver a portion of the meal bolus upfront with the remaining portion infused for a set period of time (50\% delivered for $4 \mathrm{~h}$ in this study), which may be beneficial for high-fat meals that may have delayed gastric emptying, ${ }^{18}$ or for children with unpredictable eating patterns. The purpose of the extended bolus in the OL and HCL setting is the same: to reduce the risk of early hypo- glycemia and delayed hyperglycemia that may be encountered with a standard bolus for certain types of meals. Announcing a meal with an extended bolus gives the AP system more information about the anticipated characteristics and insulin requirements of the meal. The use of extended boluses for high-fat meals during HCL in this study was safe. The extended portion of the bolus was canceled in some subjects according to the algorithm safety constraint implemented in this study, which has informed future development of the integration of extended boluses within the personalized MPC algorithm. The ability to use an extended bolus as part of an AP system may provide additional flexibility to users to manage their diabetes according to their preferences and lifestyle.

For overall glycemic outcomes, a review of the literature indicates that HCL systems may be expected to achieve at least $70 \%$ of sensor glucose values between 70 and $180 \mathrm{mg} /$ $\mathrm{dL}$ with $<4 \%$ of values $<70 \mathrm{mg} / \mathrm{dL},{ }^{3}$ a $\mathrm{CV}<36 \%,{ }^{26}$ and a mean glucose of $\leq 155 \mathrm{mg} / \mathrm{dL}$, equivalent to an estimated HbA1c of $7.0 \% .^{27,28}$ This study exceeded each of these performance metrics, with $76.1 \% \pm 8.0 \%$ of sensor glucose values in the target range of $70-180 \mathrm{mg} / \mathrm{dL}$ overall. These 


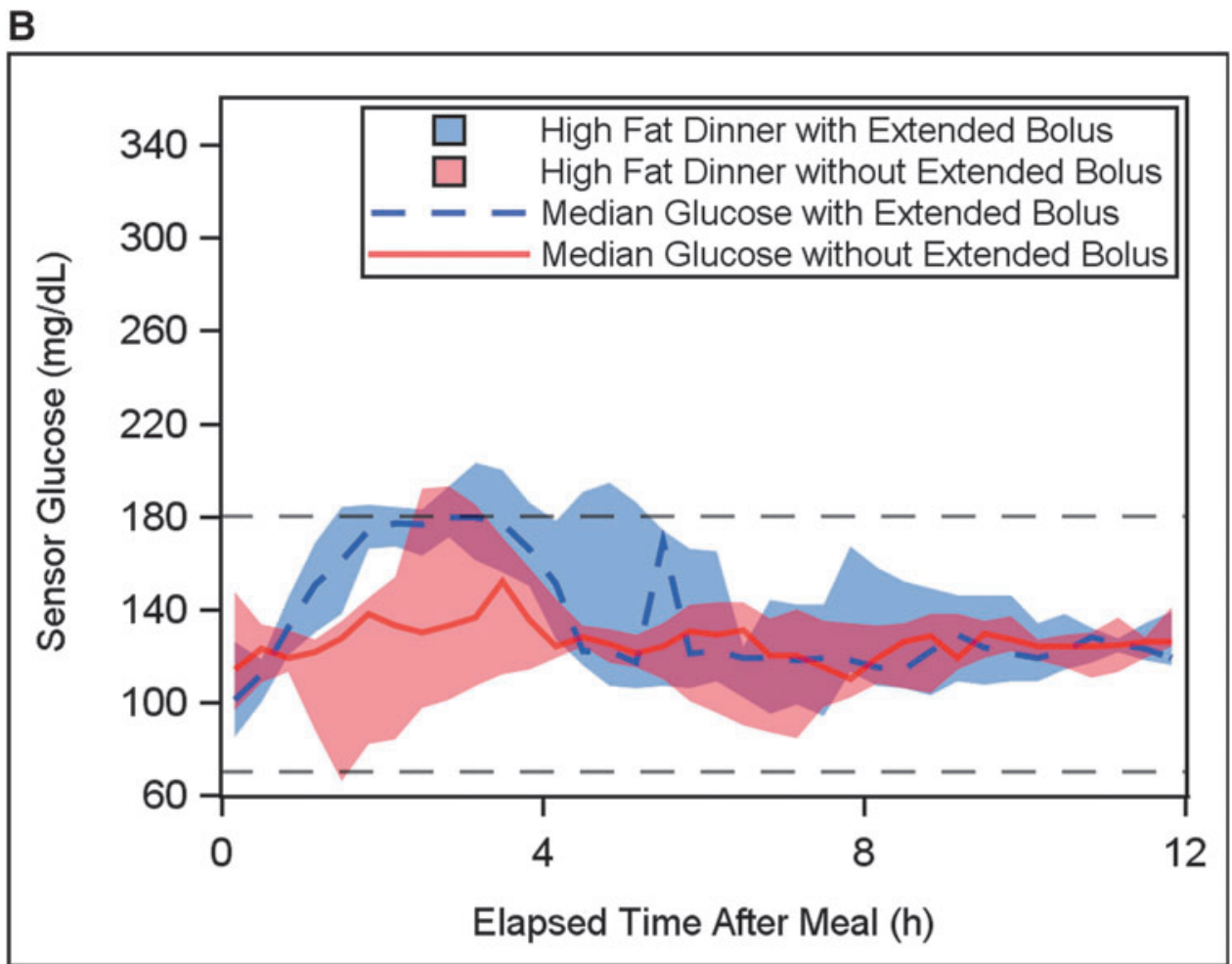

Percent of Subjects in Glycemic Ranges by Elapsed Time After Meal (h)
\begin{tabular}{|c|c|c|c|c|c|c|}
\hline & 0 to 4 Hours & \multicolumn{2}{c|}{$\begin{array}{c}\mathbf{4} \text { to } 8 \text { Hours } \\
8 \text { to } 12 \text { Hours }\end{array}$} \\
\hline $\begin{array}{c}\text { CGM } \\
(\mathrm{mg} / \mathrm{dL})\end{array}$ & $\begin{array}{c}\text { Extended } \\
\text { Bolus }\end{array}$ & $\begin{array}{c}\text { Standard } \\
\text { Bolus }\end{array}$ & $\begin{array}{c}\text { Extended } \\
\text { Bolus }\end{array}$ & $\begin{array}{c}\text { Standard } \\
\text { Bolus }\end{array}$ & $\begin{array}{c}\text { Extended } \\
\text { Bolus }\end{array}$ & $\begin{array}{c}\text { Standard } \\
\text { Bolus }\end{array}$ \\
\hline$<54$ & $0.0 \%$ & $14.3 \%$ & $0.0 \%$ & $0.0 \%$ & $0.0 \%$ & $0.0 \%$ \\
\hline$<70$ & $0.0 \%$ & $28.6 \%$ & $28.6 \%$ & $0.0 \%$ & $0.0 \%$ & $0.0 \%$ \\
\hline$>180$ & $71.4 \%$ & $28.6 \%$ & $28.6 \%$ & $0.0 \%$ & $0.0 \%$ & $14.3 \%$ \\
\hline$\geq 250$ & $0.0 \%$ & $0.0 \%$ & $0.0 \%$ & $0.0 \%$ & $0.0 \%$ & $0.0 \%$ \\
\hline
\end{tabular}

FIG. 4. Comparison of glycemic response with a standard $100 \%$ meal bolus versus an extended meal bolus for a 12-h postprandial period. Median sensor glucose response is plotted for the 12 subjects for $12 \mathrm{~h}$ after a $30-58 \mathrm{~g}$ fat dinner with an extended meal bolus (50\% bolus upfront and 50\% extended for $4 \mathrm{~h}$ ) (dashed blue line) and without an extended meal bolus ( $100 \%$ bolus upfront) (solid red line). Data are shown separately for (A) the five subjects who received the extended bolus for $>1 \mathrm{~h}$ and (B) the seven subjects for whom the extended bolus was canceled by the algorithm within $1 \mathrm{~h}$ due to the safety constraint. Each subject consumed an identical meal on the days with the standard and extended bolus. The shaded area represents the IQR. The target range of $70-180 \mathrm{mg} / \mathrm{dL}$ is indicated by black dashed lines. The percentage of subjects in various glycemic ranges (hypoglycemia $<70$ and $<54 \mathrm{mg} / \mathrm{dL}$, and hyperglycemia $>180$ and $\geq 250 \mathrm{mg} / \mathrm{dL}$ ) during $4 \mathrm{~h} \mathrm{seg}$ ments of the postprandial period is tabulated for each bolus type (extended and standard) beneath each graph.

glycemic control metrics were met in this study even in the presence of overestimated and missed meal boluses that may occur when an AP system is used in a free-living outpatient environment.

The limitations of this study include not having a control arm with a $130 \%$ overestimated meal bolus, missed meal bolus, or extended meal bolus in the usual care arm (out of closed-loop). A control arm comparing with standard of care was not included as this was primarily a feasibility study testing safety of the closed-loop system. The study had a relatively short duration of HCL conducted in a supervised hotel setting. Additional challenges to the algorithm may be faced in an unsupervised environment or when the system is used for longer periods of time.

\section{Conclusions}

This feasibility study demonstrated that the Omnipod personalized MPC algorithm performed well and was safe for $54 \mathrm{~h}$ of use by adults in the outpatient hotel setting. An AP system with a flexible and responsive control algorithm may be able to minimize glycemic excursions, including both prolonged severe hyperglycemia after a missed or underestimated meal bolus, as well as hypoglycemia after an overestimated meal bolus. In this study, the system was able to maintain good glycemic control within target ranges during the postprandial period in the presence of challenging meal scenarios, including overestimated, missed, and extended meal boluses with high-fat meals. Longer term 
Table 5. Preprandial and 12-Hour Postprandial Outcomes for High-Fat Dinner with Standard $100 \%$ Versus Extended Meal Bolus

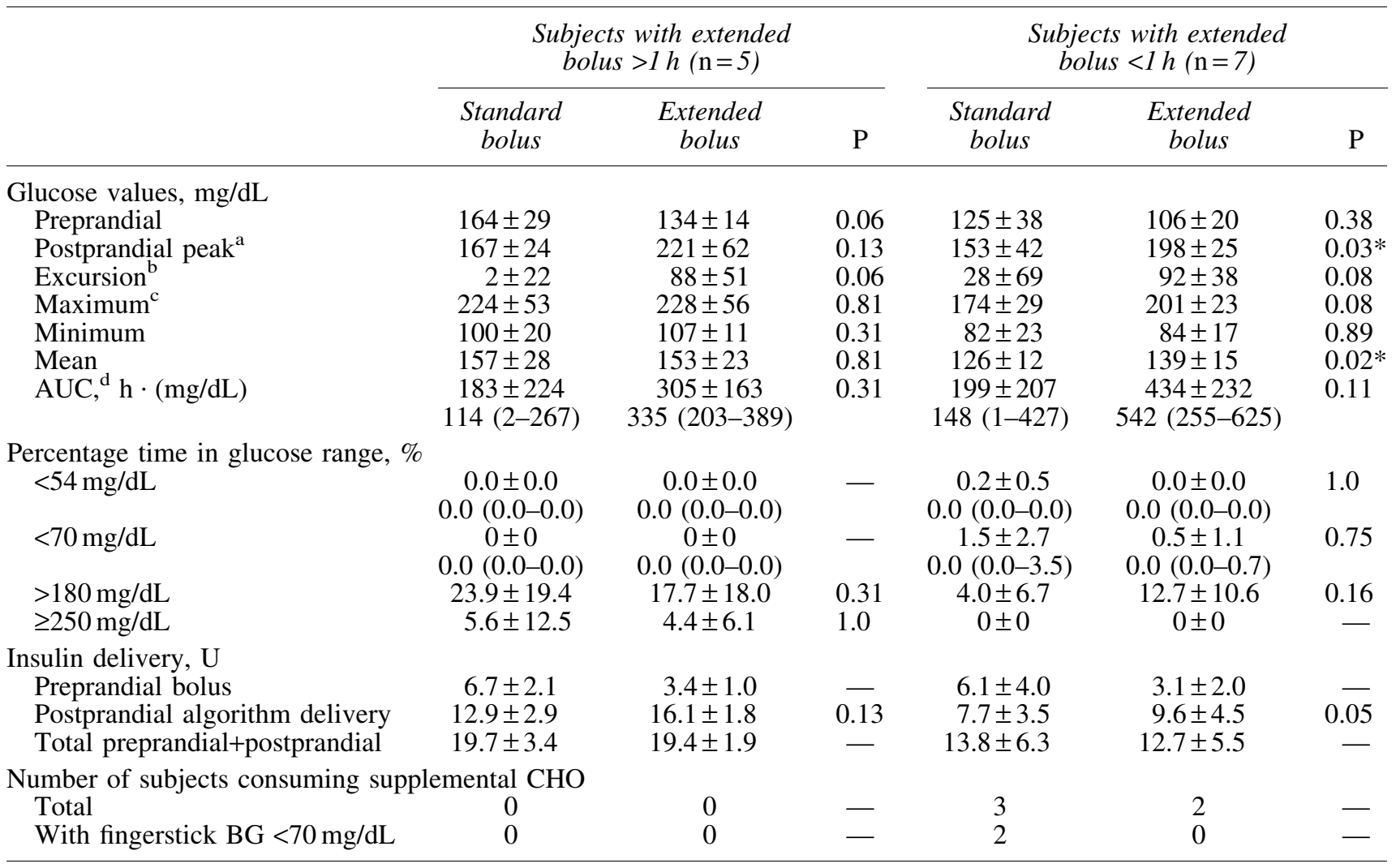

Results are sensor glucose values, mean \pm SD unless otherwise indicated; SI conversion factor to convert glucose to mmol/L, multiply by 0.0555 .

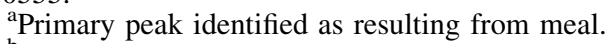

${ }^{\mathrm{b}}$ Postprandial peak minus preprandial glucose, note that this value was negative for five subjects in the standard bolus case.

${ }^{\mathrm{c}}$ Maximum sensor glucose for postprandial period.

${ }^{\mathrm{d}}$ Incremental AUC that is more than the premeal concentration level.

$* P<0.05$.

outpatient studies will assess safety and performance of the algorithm during extended use under free-living conditions in people of all ages with type 1 diabetes.

\section{Acknowledgments}

The authors thank the study participants and their families, and the dedicated staff at the participating research centers: Liana Hsu, Tatiana Marcal, Tali Jacobson, Lisa Norlander, Hyojin Min, Ryan Kingman, and Laya Ekhlaspour of the Stanford University Medical Center, Stanford, CA; Robert Slover, G. Todd Alonso, Brigitte Frohnert, Katelin Thivener, Cari Berget, and Laurel H. Messer of the Barbara Davis Center for Diabetes, University of Colorado Denver, Denver, CO; and Margie Macarewich of the Diablo Clinical Research Center, Walnut Creek, CA. We appreciate the efforts of the research and development and clinical teams at Insulet Corp., including Bonnie Dumais, Connor Gullifer, Stephanie Mandra, Todd Vienneau, and Yibin Zheng, PhD. This work was funded by Insulet Corporation.

\section{Author Disclosure Statement}

Dr. Forlenza has received research funding from Animas, Bigfoot Biomedical, Dexcom, Insulet Corp., Medtronic, Novo
Nordisk, Tandem, and Type Zero, and is a speaker and advisory board member for Dexcom.

Dr. Buckingham served as the principal investigator for the study and received research funding from Insulet Corp., and has received research support from Bigfoot Biomedical, Dexcom, Medtronic, and Tandem, and is an advisory board member for Becton Dickinson, NovoNordisk, and Sanofi.

Dr. Wadwa has received research funding from Bigfoot Biomedical, Dexcom, Insulet Corp., Lexicon Pharmaceutical, Medtronic, Novo Nordisk, Tandem, and Xeris Pharmaceutical, and is an advisory board member for Eli Lilly \& Co and Novo Nordisk, and a consultant for MannKind.

Dr. Christiansen has received research funding from Abbott Diabetes Care, Dexcom, Insulet Corp., and Medtronic.

Dr. Peyser is a consultant to Insulet Corp and has consulted for Dexcom.

Dr. Dassau is a consultant to Insulet Corp and has received research support from Dexcom, Tandem, Roche, Insulet, and Xeris.

Drs. Ly, Lee, Huyett, and Layne and Mr. O'Connor are employees of Insulet Corp. 


\section{References}

1. Iturralde E, Tanenbaum ML, Hanes SJ, et al.: Expectations and attitudes of individuals with type 1 diabetes after using a hybrid closed loop system. Diabetes Educ 2017; 43:223-232.

2. Naranjo D, Suttiratana SC, Iturralde E, et al.: What end users and stakeholders want from automated insulin delivery systems. Diabetes Care 2017;40:1453-1461.

3. Weisman A, Bai JW, Cardinez M, et al.: Effect of artificial pancreas systems on glycaemic control in patients with type 1 diabetes: a systematic review and meta-analysis of outpatient randomised controlled trials. Lancet Diabetes Endocrinol 2017;5:501-512.

4. Bergenstal RM, Garg S, Weinzimer SA, et al.: Safety of a hybrid closed-loop insulin delivery system in patients with type 1 diabetes. JAMA 2016;316:1407-1408.

5. Garg SK, Weinzimer SA, Tamborlane WV, et al.: Glucose outcomes with the in-home use of a hybrid closed-loop insulin delivery system in adolescents and adults with type 1 diabetes. Diabetes Technol Ther 2017;19:155-163.

6. Thabit H, Hovorka R: Coming of age: the artificial pancreas for type 1 diabetes. Diabetologia 2016;59:1795-1805.

7. Doyle III FJ, Huyett LM, Lee JB, et al.: Closed-loop artificial pancreas systems: engineering the algorithms. Diabetes Care 2014;37:1191-1197.

8. Messer LH, Forlenza GP, Wadwa RP, et al.: The dawn of automated insulin delivery: a new clinical framework to conceptualize insulin administration. Pediatr Diabetes 2018;19:14-17.

9. Peyser T, Dassau E, Breton M, et al.: The artificial pancreas: current status and future prospects in the management of diabetes. Ann N Y Acad Sci 2014;1311:102-123.

10. Jaser SS, Datye KA: Frequency of missed insulin boluses in type 1 diabetes and its impact on diabetes control. Diabetes Technol Ther 2016;18:341-342.

11. Olinder AL, Kernell A, Smide B: Missed bolus doses: devastating for metabolic control in CSII-treated adolescents with type 1 diabetes. Pediatr Diabetes 2009;10:142148.

12. Meade LT, Rushton WE: Accuracy of carbohydrate counting in adults. Clin Diabetes 2016;34:142-147.

13. Gingras V, Smaoui MR, Cameli C, et al.: Impact of erroneous meal insulin bolus with dual-hormone artificial pancreas using a simplified bolus strategy - a randomized controlled trial. Sci Rep 2018;8:2621.

14. Chase HP, Doyle III FJ, Zisser H, et al.: Multicenter closedloop/hybrid meal bolus insulin delivery with type 1 diabetes. Diabetes Technol Ther 2014;16:623-632.

15. Cherñavvsky DR, DeBoer MD, Keith-Hynes P, et al.: Use of an artificial pancreas among adolescents for a missed snack bolus and an underestimated meal bolus. Pediatr Diabetes 2016;17:28-35.

16. Elleri D, Biagioni M, Allen JM, et al.: Safety, efficacy and glucose turnover of reduced prandial boluses during closed-loop therapy in adolescents with type 1 diabetes: a randomized clinical trial. Diabetes Obes Metab 2015;17: 1173-1179.
17. Forlenza GP, Cameron FM, Ly TT, et al.: Fully closedloop multiple model probabilistic predictive controller artificial pancreas performance in adolescents and adults in a supervised hotel setting. Diabetes Technol Ther 2018;20:335-343.

18. Bell KJ, Smart CE, Steil GM, et al.: Impact of fat, protein, and glycemic index on postprandial glucose control in type 1 diabetes: implications for intensive diabetes management in the continuous glucose monitoring era. Diabetes Care 2015;38:1008-1015.

19. Lee JB, Dassau E, Seborg DE, et al.: Model-based personalization scheme of an artificial pancreas for type 1 diabetes applications. In: Paper Presented at: 2013 American Control Conference, June 17-19, 2013.

20. Buckingham BA, Forlenza GP, Pinsker JE, et al.: Safety and feasibility of the OmniPod hybrid closed-loop system in adult, adolescent, and pediatric patients with type $1 \mathrm{di}-$ abetes using a personalized model predictive control algorithm. Diabetes Technol Ther 2018;20:257-262.

21. Clarke WL, Cox DJ, Gonder-Frederick LA, et al.: Reduced awareness of hypoglycemia in adults with IDDM. A prospective study of hypoglycemic frequency and associated symptoms. Diabetes Care 1995;18:517-522.

22. Standards of Medical Care in Diabetes-2017. Diabetes Care 2017;40(Suppl 1):S4-S5.

23. Dassau E, Zisser H, Palerm CC, et al.: Modular artificial beta-cell system: a prototype for clinical research. J Diabetes Sci Technol 2008;2:863-872.

24. Maahs DM, Buckingham BA, Castle JR, et al.: Outcome measures for artificial pancreas clinical trials: a consensus report. Diabetes Care 2016;39:1175-1179.

25. Agiostratidou G, Anhalt H, Ball D, et al.: Standardizing clinically meaningful outcome measures beyond $\mathrm{HbA} 1 \mathrm{c}$ for type 1 diabetes: a consensus report of the American Association of Clinical Endocrinologists, the American Association of Diabetes Educators, the American Diabetes Association, the Endocrine Society, JDRF International, The Leona M. and Harry B. Helmsley Charitable Trust, the Pediatric Endocrine Society, and the T1D Exchange. Diabetes Care 2017;40:1622.

26. Monnier L, Colette C, Wojtusciszyn A, et al.: Toward defining the threshold between low and high glucose variability in diabetes. Diabetes Care 2017;40:832-838.

27. Beck RW, Connor CG, Mullen DM, et al.: The fallacy of average: how using HbA1c alone to assess glycemic control can be misleading. Diabetes Care 2017;40:994-999.

28. Jaeb Center for Health Research: HbA1c Estimator. https:// www.jaeb.org/a1c (accessed December 11, 2017).

Address correspondence to:

Bruce A. Buckingham, MD

Division of Endocrinology and Diabetes Stanford School of Medicine 780 Welch Road Palo Alto, CA 94305

E-mail: bbendo@stanford.edu 